\title{
BMJ Open Metformin use and long-term risk of benign prostatic hyperplasia: a population-based cohort study
}

\author{
Mette Nørgaard (D) , Bianka Darvalics, Reimar Wernich Thomsen
}

To cite: Nørgaard M, Darvalics B, Thomsen RW. Metformin use and longterm risk of benign prostatic hyperplasia: a populationbased cohort study. BMJ Open 2020;10:e041875. doi:10.1136/ bmjopen-2020-041875

- Prepublication history and additional material for this paper is available online. To view these files, please visit the journal online (http://dx.doi.org/10. 1136/bmjopen-2020-041875).

Received 19 June 2020 Revised 26 0ctober 2020 Accepted 08 December 2020

Check for updates

(C) Author(s) (or their employer(s)) 2020. Re-use permitted under CC BY-NC. No commercial re-use. See rights and permissions. Published by BMJ.

Department of Clinical Epidemiology, Department of Clinical Medicine, Aarhus University and Aarhus University Hospital, Aarhus, Denmark

Correspondence to Professor Mette Nørgaard; mn@clin.au.dk

\section{ABSTRACT}

Objective To assess whether metformin use affects risk of benign prostatic hyperplasia (BPH) by comparing the risk of $\mathrm{BPH}$ in men with type 2 diabetes who initiated first-line treatment with either metformin or sulfonylurea monotherapy between 2000 or 2006 in Northern Denmark. In this period, sulfonylurea and metformin were both frequently used as first-line glucose-lowering drug (GLD) treatment.

Design A population-based cohort study.

Setting Northern Denmark.

Participants All men who filled at least two prescriptions for metformin or for sulfonylurea, respectively, during their first 6 months of GLD treatment. Follow-up started 6 months after treatment start.

Primary outcome measures Rates of subsequent $\mathrm{BPH}$, identified based on community prescriptions for BPHrelated treatment or hospital $\mathrm{BPH}$ diagnoses, and rates of transurethral resection of the prostate (TURP). Rates in metformin and sulfonylurea users were compared overall and stratified by 6-month haemoglobin A1c ( $\mathrm{HbA} 1 \mathrm{c}$, using Cox regression and an intention-to-treat (ITT) approach and an as-treated analysis.

Results During follow-up, less than five persons were lost to follow-up due to emigration. In 3953 metformin initiators with a median follow-up of 10 years, the 10-year cumulative BPH incidence was $25.7 \%(95 \% \mathrm{Cl} 24.2$ to 27.1). Compared with 5958 sulfonylurea users (median follow-up 8 years, 10-year cumulative incidence $27.4 \%$ (95\% Cl 26.2 to 28.6)), the crude HR for BPH was 0.83 (95\% Cl 0.77 to 0.89 ) and adjusted HR in the ITT analyses was 0.97 (95\% $\mathrm{Cl} 0.88$ to 1.06). For TURP, the adjusted HR was 0.96 (95\% $\mathrm{Cl} 0.63$ to 1.46). In the as-treated analysis, adjusted HR for BPH was 0.91 (95\% $\mathrm{Cl} 0.81$ to 1.02$)$.

Conclusions Compared with sulfonylurea, metformin did not substantially reduce the incidence of BPH in men with diabetes.

\section{INTRODUCTION}

Benign prostatic hyperplasia (BPH) associated with lower urinary tract symptoms is a common condition estimated to affect around 20\% of American men aged 30-79 years. ${ }^{1}$ Risk factors associated with dysmetabolism and low-grade inflammation, including obesity, high blood glucose, low exercise and poor diet, seem to contribute substantially to the development of BPH and lower urinary

\section{Strengths and limitations of this study}

- The study used population-based data from two well-defined Danish regions.(expressed per 100

- Use of nationwide medical registries allowed long and virtually complete follow-up.

- Initiators of glucose-lowering drugs (GLDs) could be identified in a calendar period in which both metformin and sulfonylurea were recommended and used as first-line treatment which minimised confounding by indication.

- Benign prostatic hyperplasia was defined both based on hospital-related diagnoses and by prescriptions for relevant medication.

- We categorised treatment based on the choice of GLD during the first 6 months after treatment start applying an intention to treat principal but we also included an as-treated analysis.

tract symptoms. ${ }^{23}$ Moreover, prostatic inflammation is likely a key factor in the development of BPH and also prostate cancer. ${ }^{4}$ Accordingly, it has been hypothesised that insulin resistance and increased fasting plasma insulin are promoters of both $\mathrm{BPH}$ and prostate cancer. ${ }^{5}$

Metformin is suggested to have various beneficial therapeutic effects. ${ }^{6}$ Among men with type 2 diabetes, some observational studies have suggested that use of metformin reduces the risk of prostate cancer, compared with use of other glucose-lowering drugs (GLDs) ${ }^{7-9}$ while others found no clear association. ${ }^{10-12}$ A recent study found that metformin inhibits the proliferation of human prostate epithelial cells, ${ }^{13}$ and thus may reduce the BPH development as well as development of prostate cancer. Yet, few studies have examined the association between use of metformin and risk of BPH in diabetic men. A cohort study including 192457 male veterans with type 2 diabetes and 259995 person-years (PY) of follow-up found no association between use of thiazolidinediones or metformin and new medical or surgical treatment for $\mathrm{BPH}$, when compared with use of sulfonylurea. ${ }^{14}$ While, 
a recent cohort study from South Korea found among 211648 men with newly diagnosed BPH that men with type 2 diabetes in metformin treatment had lower risk of progression to prostatectomy than both men without type 2 diabetes and men with type 2 diabetes with no metformin treatment. ${ }^{15}$

Comparing the effects of different GLDs in observational studies is complicated by the fact that the underlying indications/contraindications may differ between the drugs. ${ }^{16}$ Compared with sulfonylurea, metformin has a more favourable effect on body weight and insulin resistance, and patients receiving metformin are therefore likely to have a higher prevalence of obesity and a higher plasma insulin level than users of sulfonylurea. ${ }^{17}$ At least since 2011, metformin has been unequivocally consensus recommended as first-choice treatment in type 2 diabetes in Denmark, based on evidence from the UK Prospective Diabetes Study $1998^{18}$ and its 10-year follow-up in 2008. ${ }^{19}$ Already in the mid-2000s, however, the European Association for the Study of Diabetes and the American Diabetes Association recommended use of metformin as first-line drug. ${ }^{20}{ }^{21}$ Previously-in particular during the first half of the 2000s-metformin and sulfonylurea were both widely recommended and used as first-line treatment for type 2 diabetes in Denmark. ${ }^{22}$ We therefore conducted a large population-based cohort study to examine the long-term risk of $\mathrm{BPH}$ in men with type 2 diabetes who initiated pharmacotherapy with either metformin or sulfonylurea between 2000 and 2006 in Northern Denmark. Our hypothesis was that use of metformin was associated with a lower BPH rate than use of sulfonylurea in men with type 2 diabetes.

\section{METHODS}

\section{Setting}

We conducted a population-based cohort study among men with type 2 diabetes living in Northern Denmark using Danish medical databases. Northern Denmark consists of two regions, the Central Denmark region and the North Denmark region, with approximately 700000 male inhabitants. All residents are provided free taxsupported access to healthcare. All Danish residents are, at birth or on immigration, assigned a unique personal identifier, the Civil Personal Register (CPR) number, by the Danish Civil Registration System (CRS) ${ }^{23}$ This identifier allows unambiguous linkage of data at the individual level. The CRS additionally tracks changes in vital status, residence and migration for the entire Danish population on a daily basis. The Danish National Patient Registry (DNPR) has recorded all admissions to all Danish hospitals since $1977 .{ }^{24}$ Hospital outpatient and emergency room visits have been included in the DNPR since 1995. Diagnoses are classified according to the International Classification of Diseases, Eighth Revision (ICD-8) until the end of 1993 and Tenth Revision (ICD10) thereafter.

\section{Assembly of the cohort}

We included all men 30 years or older with incident type 2 diabetes, who received their first GLD treatment between 1 January 2000 and 31 December 2006, corresponding to the time period when the Danish guidelines recommended both metformin and sulfonylurea as firstline treatment for type 2 diabetes. ${ }^{22}$ We defined incident type 2 diabetes as either a first record in the DNPR of a diabetes-associated inpatient admission (data available from 1977) or outpatient clinic contact (data available from 1995) or the first record of a GLD prescription in the Aarhus University Prescription Database (data available from 1996). ${ }^{25}$ Thus, patients with a GLD prescription in the 1996-1999 period were excluded.

\section{GLD treatment}

We categorised patients according to their first GLD treatment, metformin or sulfonylurea. To avoid including patients who switched or augmented GLD treatment very early (potentially due to adverse reactions or insufficient early glucose control), we required the patients to receive either metformin or sulfonylurea monotherapy for at least 6 months by requiring two prescriptions for the same type of GLD within 6 months after treatment start. Accordingly, we did not include patients who started combination therapy or who switched type of treatment away from metformin or sulfonylurea monotherapy, respectively, during the first 6 months of treatment. First, we used an intention-to-treat (ITT) principle and ignored treatment after the first 6 months when categorising the patients according to treatment exposure. Next, we categorised patients 'as treated' so that patients were considered exposed with a specific GLD from first prescription of this GLD until the end of the last prescription of this type of GLD (based on the estimated number of days covered by the pack size of a filled prescription) + a washout period.

\section{Outcome}

Our primary outcome was first-time BPH defined as the first of a first-time hospital-related discharge diagnosis (see online supplemental material 1 for codes) recorded in DNPR or a first-time filled community pharmacy prescription for $\mathrm{BPH}$ treatment (alpha blockers or 5-alpha reductase inhibitors).

As a secondary outcome, we included information on transurethral resection of the prostate (TURP). Additionally, we examined hospital-related BPH diagnoses separately. Finally, we identified all hospital contacts with a first-time diagnosis code of urinary retention since this may be a first acute manifestation of BPH but can also be caused by neuropathic bladder disease ${ }^{26}$ and we analysed $\mathrm{BPH}$ and acute urinary retention as a composite outcome. We excluded men with any of these outcomes before start of follow-up.

\section{Diabetes severity}

We assessed diabetes severity at the time of follow-up start 6 months after first GLD treatment, using diabetes 
duration (see below), the presence of microvascular and macrovascular diabetes complications (see online supplemental material 1 for codes) and glycaemic control, that is, the latest haemoglobin A1c (HbAlc) measured in the year prior to start of follow-up. HbAlc levels were registered in the clinical laboratory information system database (LABKA) which contains results of all analyses of blood samples drawn from primary care and hospitalised patients and analysed in hospital laboratories in the Northern and Central Denmark regions. ${ }^{27}$ We categorised HbAlc into three levels $(<7 \%(53 \mathrm{mmol} / \mathrm{mol}), 7 \%-<8 \%$ (53-<64 mmol $/ \mathrm{mol}), \geq 8 \%(64 \mathrm{mmol} / \mathrm{mol}))$ based on the American Diabetes Association-recommended goals for $\mathrm{HbAlc}^{28}$ and we categorised those with missing variables separately.

\section{Other covariates}

We obtained information on age from the CRS. From the DNPR, we included the 19 major comorbidities included in the Charlson Comorbidity Index (CCI), based on each cohort member's entire hospital contact history prior to his index date and calculated the patient's CCI score $(0,1$, $2+)$. We also included information on previous ischaemic heart disease (yes/no), cerebrovascular disease (yes/no), chronic obstructive pulmonary disease (yes/no), renal disease (yes/no) along with other covariates potentially associated with $\mathrm{BPH}$ or prostatic inflammation: microvascular and macrovascular diabetes complications not included in the CCI; diabetes duration (if a hospital diagnosis of diabetes was present before the GLD initiation/index date); a hospital diagnosis of obesity (yes/ no); alcoholism-related disorders (yes/no); use of immunosuppressive drugs (yes/no), use of oral corticosteroids (yes/no) and use of statins (yes/no); marital status as a marker of social support (married/never married/ divorced/widowed) and calendar period of GLD initiation (2000-2002/2003-2006).

\section{Statistical analyses}

Follow-up started 6 months after the date of first GLD treatment. We tabulated characteristics at the start of follow-up for users of metformin and sulfonylurea, respectively.

The men were followed until the outcome of interest, death, emigration or end of study (7 October 2016), whichever came first. The outcome of interest could be a diagnosis of $\mathrm{BPH}$, a diagnosis of $\mathrm{BPH}$ and/or a $\mathrm{BPH}$ related prescription, and a diagnosis of $\mathrm{BPH}$ and/or a BPH-related prescription and/or acute urinary retention, respectively, or it could be a TURP.

We computed incidence rates (IRs) for BPH (separately for the three BPH definitions and for TURP, by dividing the number of incident outcome events by total exposed patient-time during follow-up (expressed per 1000 PY at risk). We used an ITT approach in our main analysis in which we carried the GLD treatment used at follow-up start 6 months after GLD initiation (metformin or sulfonylurea) forward. We constructed cumulative incidence curves to illustrate time to $\mathrm{BPH}$ and/or $\mathrm{BPH}$ treatment while treating death as a competing risk.

We also conducted an as-treated analysis in which a patient was considered exposed to a certain GLD as long as the prescription continued, based on the estimated number of days covered by the pack size of a filled prescription + a 30-day washout period that accounted for overlapping prescriptions and irregular drug use. In sensitivity analyses, we changed the washout period to 0 and 90 days, respectively. In this analysis, we censored the patient if another GLD was added. Additional censoring criteria were metformin or sulfonylurea treatment cessation and crossover to the other study drug. As alpha blockers may be used for other indications than symptomatic BPH, we also conducted a sensitivity analysis in which we defined $\mathrm{BPH}$ as either a recorded diagnosis of BPH or a prescription for a 5 -alpha reductase inhibitor.

We computed HRs of each definition of BPH (with 95\% CIs) and of TURP associated with the exposure categories described above (both ITT and as treated), using Cox regression with sulfonylurea initiation as reference with adjustment for age, marital status, diabetes duration, comorbidity (CCI level), presence of microvascular or macrovascular complications, HbAlc level achieved at start of follow-up, obesity, alcohol-related disease, use of glucocorticoids, use of statins and calendar period of first GLD treatment, and we also stratified by HbAlc level achieved at start of follow-up. We used a complete case analysis to handle missing data. As sensitivity analysis, we additionally analysed the data using the missing indicator method.

\section{Patient and public involvement}

Patients or the public were not involved in the design, or conduct, or reporting or dissemination plans of our research.

\section{RESULTS}

In the Northern Denmark cohort, we identified 9911 men without BPH who filled at least two prescriptions within 6 months after treatment start for either metformin or sulfonylurea in 2000-2006. Of these, 3953 (40\%) started metformin treatment and $5987(60 \%)$ started sulfonylurea (table 1).

The median age was 57 years (IQR 49-65) for metformin users and 63 years (IQR 54-72) for sulfonylurea users. In addition to being younger, metformin users had less microvascular (5.9\% vs $9.0 \%$ ) and macrovascular complications (22.2\% vs $28.1 \%$ ). Median HbAlc levels achieved at start of follow-up were similar $6.9 \%(52 \mathrm{mmol} / \mathrm{mol})$ versus $6.8 \%(51 \mathrm{mmol} / \mathrm{mol})$. The prevalence of hospitalrecorded obesity was highest in metformin users while the prevalence of other included comorbidities was higher in sulfonylurea users (table 1). Metformin users had highest prevalence of statin use, $38.2 \%$ versus $27.7 \%$ in sulfonylurea users but had slightly lower prevalence of hospitaldiagnosed cardiovascular disease. 
Table 1 Baseline characteristics of men initiating either metformin or sulfonylurea monotherapy

\begin{tabular}{lll}
\hline Characteristics & $\begin{array}{l}\text { Metformin } \\
\text { N (\%) }\end{array}$ & $\begin{array}{l}\text { Sulfonylurea } \\
\text { N (\%) }\end{array}$ \\
\hline Total & 3953 & 5958 \\
\hline Median age (IQR) & $57(49-65)$ & $63(54-72)$ \\
\hline Age group & & \\
\hline $30-<50$ years & $1003(25.4)$ & $822(13.8)$ \\
\hline $50-<70$ years & $2373(60.0)$ & $3267(54.8)$ \\
\hline$\geq 70$ years & $577(14.6)$ & $1869(31.4)$ \\
\hline Year of study inclusion & & \\
\hline $2000-2002$ & $1104(27.9)$ & $2726(45.8)$ \\
\hline $2003-2006$ & $2849(72.1)$ & $3232(54.2)$ \\
\hline Marital status & & \\
\hline Married & $2435(61.6)$ & $3890(65.3)$ \\
\hline Never married & $681(17.2)$ & $765(12.8)$ \\
\hline Divorced & $53613.6)$ & $657(11.0)$ \\
\hline Widowed & $223(5.6)$ & $597(10.0)$ \\
\hline Missing & $78(2.0)$ & $49(0.8)$ \\
\hline
\end{tabular}

Diabetes duration

\begin{tabular}{|lll|}
\hline Newly diagnosed & $2328(58.9)$ & $3759(63.1)$ \\
\hline$<1$ year & $1047(26.5)$ & $1367(22.9)$ \\
\hline 1-5 years & $409(10.3)$ & $532(8.9)$ \\
\hline$>5$ years & $169(4.3)$ & $300(5.0)$ \\
\hline Diabetes complications & & \\
\hline Microvascular & $235(5.9)$ & $535(9.0)$ \\
\hline Macrovascular & $878(22.2)$ & $1677(28.1)$ \\
\hline Haemoglobin A1c level & & \\
\hline$<7 \%$ (53 mmol/mol) & $1542(39.0)$ & $2243(37.6)$ \\
\hline 7-<8\% (53-<64 mmol/mol) & $769(19.5)$ & $980(16.4)$ \\
\hline$\geq 8 \%$ (64 mmol/mol) & $561(14.2)$ & $839(14.1)$ \\
\hline Missing & $1081(27.3)$ & $1896(31.8)$ \\
\hline Comorbidities & & \\
\hline Myocardial infarction & $304(7.7)$ & $624(10.5)$ \\
\hline $\begin{array}{l}\text { Congestive heart failure } \\
\text { Peripheral vascular disease }\end{array}$ & $175(4.4)$ & $435(7.3)$ \\
\hline Cerebrovascular disease & $299(7.6)$ & $342(5.7)$ \\
\hline Chronic pulmonary disease & $305(7.7)$ & $536(9.2)$ \\
\hline $\begin{array}{l}\text { Cancer } \\
\text { Obesity }\end{array}$ & $138(3.5)$ & $365(6.1)$ \\
\hline $\begin{array}{l}\text { Alcoholism-related } \\
\text { disorders }\end{array}$ & $501(12.7)$ & $313(5.3)$ \\
\hline Charson Comorbidity (4.7) & $328(5.5)$ \\
\hline
\end{tabular}

Charlson Comorbidity Index Score

\begin{tabular}{lll}
0 & $1910(48.3)$ & $2781(46.7)$ \\
\hline $1-2$ & $1677(42.4)$ & $2270(38.1)$ \\
$>2$ & $366(9.3)$ & $907(15.2)$ \\
\hline Statins ever use & $1511(38.2)$ & $1652(27.7)$ \\
Immunosuppressants & $25(0.6)$ & $51(0.9)$ \\
\hline
\end{tabular}

Continued
Table 1 Continued

\begin{tabular}{cll} 
Characteristics & $\begin{array}{l}\text { Metformin } \\
\text { N (\%) }\end{array}$ & $\begin{array}{l}\text { Sulfonylurea } \\
\text { N (\%) }\end{array}$ \\
\hline Oral corticosteroids & $228(5.8)$ & $495(8.3)$ \\
\hline
\end{tabular}

Treatment initiation was defined as at least two prescriptions for the same drug and no prescriptions for other glucose lowering drugs prescribed during the first 6 months of treatment.

Characteristics were measured at date of treatment start except haemoglobin A1c level which was measured at start of follow-up 6 months after treatment start.

In the ITT analyses within up to 17 years of follow-up (median 10 years) and less than five persons lost to follow-up due to emigration, 1061 metformin users had a hospital-related BPH diagnosis or a BPH-related prescription corresponding to an IR per $1000 \mathrm{PY}$ of 33.36 (95\% CI 31.35 to 35.37 ) and the 10-year cumulative incidence was $25.7 \%$ (95\% CI 24.2 to 27.1 ) (table 2 and figure 1 ). The IR per $1000 \mathrm{PY}$ in users of sulfonylurea was $40.32(95 \%$ CI 38.45 to 42.20 ) and the 10-year cumulative incidence of hospital-related BPH was $27.4 \%$ (95\% CI 26.2 to 28.6). Compared with sulfonylurea users, the crude HR for BPH (diagnosis or a BPH-related prescription) was 0.83 (95\% CI 0.77 to 0.89$)$, and after adjustment, it was $0.97(95 \%$ CI 0.88 to 1.06 ).

The number of metformin users with a hospital-related diagnosis of BPH was 196, yielding an IR per $1000 \mathrm{PY}$ of 5.30 (95\% CI 4.56 to 6.04 ) and a 10-year cumulative incidence of $4.7 \%$ (95\% CI 4.1 to 5.5). Compared with sulfonylurea users, the crude HR for hospital-related BPH was $0.62(95 \%$ CI 0.53 to 0.74$)$ and after adjustment it was 0.87 (95\% CI 0.70 to 1.08 ).

When combining urinary retention and BPH (diagnosis and/or BPH-related prescriptions), the adjusted HR was 0.97 (95\% CI 0.88 to 1.07$)$. For TURP, the adjusted HR was 0.96 (95\% CI 0.63 to 1.46 ) (table 2 ).

When we included GLD treatment as a time-varying exposure and assumed a 30-day washout period, metformin users had a marginally lower BPH rate (adjusted HR $=0.91$ (95\% CI 0.81 to 1.02$)$ ). For hospitalrelated $\mathrm{BPH}$, the adjusted $\mathrm{HR}$ was 0.75 (95\% CI 0.58 to $0.96)$ and for TURP the adjusted HR was 0.83 (95\% CI 0.50 to 1.35 ) (table 2). Changing the washout period to 0 days and 90 days, respectively, only marginally changed these estimates. Defining BPH as either a recorded $\mathrm{BPH}$ diagnosis or a prescription for a 5-alpha reductase inhibitor without including alpha blockers lowered the BPH rate per $1000 \mathrm{PY}$ to 8.24 (95\% CI 7.31 to 9.17 ) for metformin and 12.42 (95\% CI 11.46 to 13.39 ) for sulfonylurea in the ITT analyses and a corresponding adjusted HR of 0.92 (95\% CI 0.78 to 1.10 ). In the as-treated analysis, the adjusted HR was 0.85 (95\% CI 0.70 to 1.04 ).

When we stratified by HbA1c level in the ITT analyses, we observed a slightly lower risk of hospital-related $\mathrm{BPH}$ diagnoses or use of BPH-related prescriptions in users of metformin with $\mathrm{HbAlc}$ below $<7 \%$ (53 mmol/ 
Table 2 Occurrence of benign prostatic hyperplasia in men with diabetes according to treatment initiation with metformin or sulfonylurea

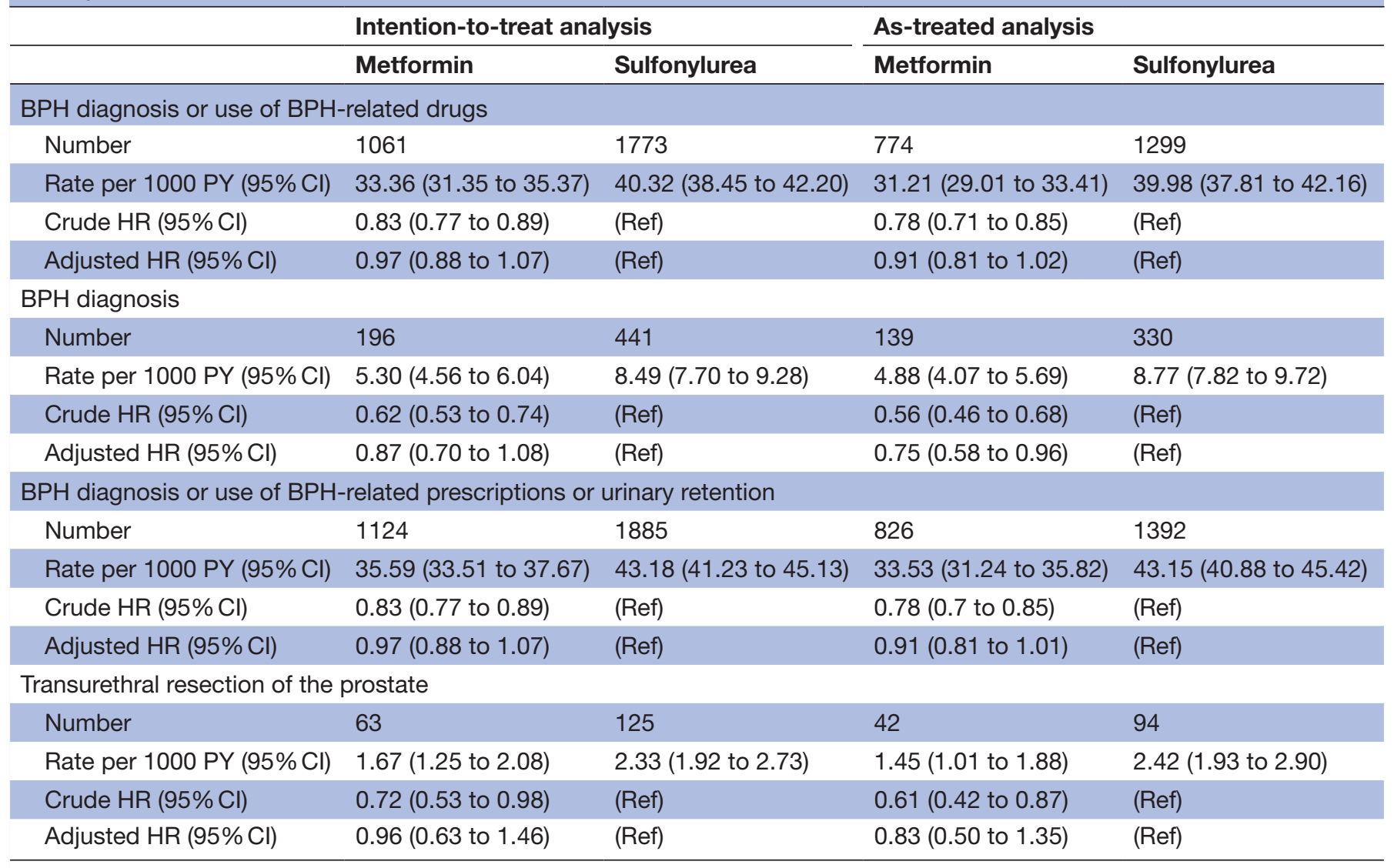

Numbers, rates per 1000 person-years (PY) and HRs of benign prostatic hyperplasia (BPH) within up to 17 years of follow-up in men with diabetes according to initial treatment with metformin or sulfonylurea (intention to treat) and analysed in an as-treated approach (ie, timevarying exposure including a 30-day washout period).

HRs were adjusted for age, Charlson Comorbidity Index Score, calendar period of diagnosis, marital status, HbA1c level, microvascular and macrovascular complications, obesity and alcohol-related disease, use of corticosteroids, use of statins and diabetes duration.

mol) compared with sulfonylurea user with HbA1c below $<7 \%(53 \mathrm{mmol} / \mathrm{mol})$, adjusted HR $0.91 \quad(95 \% \quad 0.80$ to 1.03), while there was no beneficial effect among those with HbAlc $\geq 7 \%$ (53 $\mathrm{mmol} / \mathrm{mol})$ (table 3 ). Similar results were found in the as-treated analyses with a 30-day washout period with use of metformin being associated with a slightly lower risk of a hospital-related BPH diagnosis or use of BPH-related prescriptions compared with use of sulfonylurea ( $\mathrm{HR}=0.87$ (95\% CI 0.76 to 1.00$)$ ) in patients with an $\mathrm{HbAlc}<7 \%$ (53 $\mathrm{mmol} / \mathrm{mol}$ ) (table 3 ).

Using the missing indicator method instead of complete case analysis to account for missing HbAlc values did not affect the estimates. In the ITT analysis, the adjusted HR of $\mathrm{BPH}$ (diagnosis or a BPH-related prescription) was 0.97 (95\% CI 0.90 to 1.06$)$ in the missing indicator analysis and 0.97 (95\% CI 0.88 to 1.06 ) in the complete case analysis.

\section{DISCUSSION}

In this population-based cohort study including more than 9000 men with type 2 diabetes who started either metformin or sulfonylurea treatment as monotherapy in 2000-2006, we could not confirm our hypothesis that users of metformin had substantially lower BPH rate than users of sulfonylurea.

\section{Comparison with the exsting literature}

The results from our study with much longer follow-up (median 10 years) largely supports the previous findings by Murff et alfrom the US national Veterans Health Administration database ${ }^{14}$ of no overall association between type of GLD treatment and BPH over a mean follow-up of 1.4 years. Since we additionally took glycaemic control into consideration, our findings add to the existing literature.

Due to the shared biological mechanisms of BPH and cancer, our results also indirectly add to the uncertainty regarding a causal role of metformin in prostate cancer. A recent meta-analysis found no association between metformin use and prostate cancer risk (Relative risk was $0.97,95 \%$ CI 0.80 to 1.16 ) but had significant heterogeneity between studies. ${ }^{29}$ Similarly, another systematic review included a comprehensive bias evaluation and concluded that the studies least likely to be affected by bias did not support a causal effect of metformin on cancer risk. ${ }^{30}$ A recent Taiwanese study found that treatment 


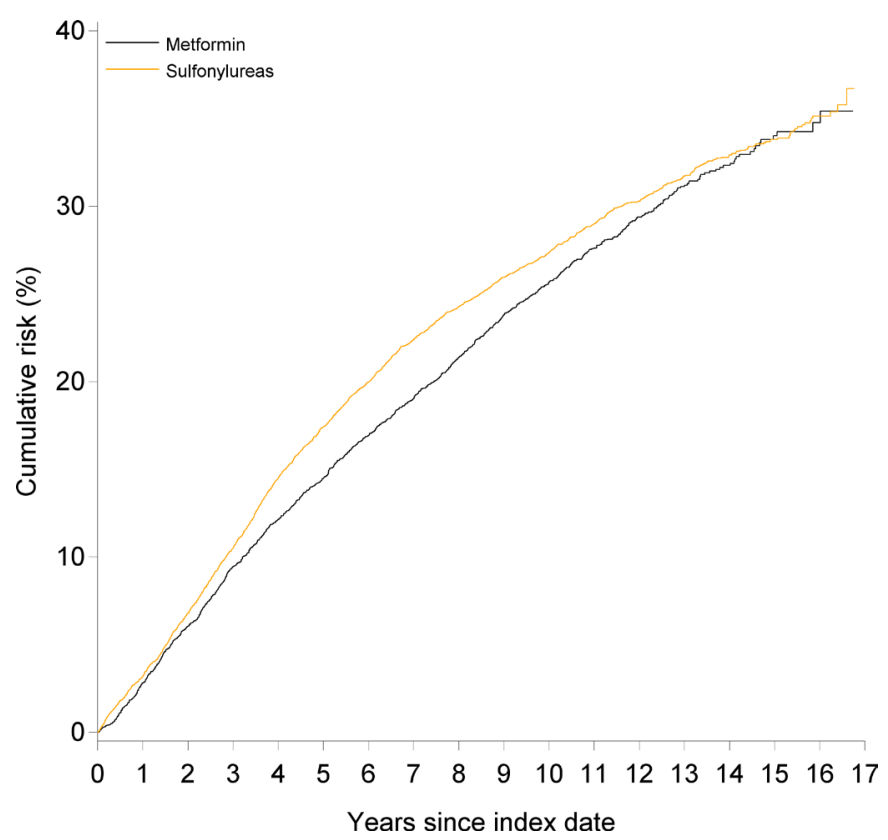

Figure 1 Cumulative incidence of a hospital-related diagnosis of benign prostatic hyperplasia (BPH) or a prescription for $\mathrm{BPH}$-related treatment in men with type 2 diabetes according to metformin or sulfonylurea treatment. Death is regarded as a competing risk.

with metformin reduced the risk of prostate cancer in men with type 2 diabetes and BPH (adjusted HR of 0.69 $(95 \%$ CI $0.49,0.96))^{9}$ but found a similar effect of traditional Chinese medicine which also points to a non-causal explanation. Thus, this issue remains unsettled.

\section{Strengths and weaknesses}

Use of nationwide medical registries allowed us to conduct a large population-based cohort study with long and virtually complete follow-up. Patients with type 2 diabetes can be identified with at least $90 \%$ completeness using Danish registries ${ }^{31}$ and the positive predictive value is $>95 \%$, with general practitioners registration as the gold standard. To minimise confounding by indication, we identified GLD initiators in a calendar period in which both metformin and sulfonylurea were recommended and used as firstline treatment. Still, our study has some weaknesses that should be considered. We identified men with BPH partly by diagnosis codes recorded in a hospital-based setting, and these codes may not be entirely accurate. However, the positive predictive values of other diagnosis codes in the group of urogenital diseases are between $75 \%$ and $100 \%$ in DNPR. ${ }^{32}$ We additionally included patients who were identified as having BPH based on the redemption of a prescription for BPH-related medication. Still, we may have missed men with untreated $\mathrm{BPH}$ and no contact to the hospital system. Since we do not expect the proportion of untreated BPH patients to vary by type of GLD treatment, we do not, however, expect this to bias our relative estimates.

Since we only included men who remained on metformin or sulfonylurea monotherapy for the first 6 months of follow-up, our results does not address men with more advanced diabetes. Yet, we had a median follow-up of 10 years and were able to follow some men for up to 17 years so we did not only include information on early stage diabetes and when we stratified by achieved HbA1c we did not see any BPH protective effect of metformin in those with poor glycaemic control.

We included BPH medication as part of our outcome definition but even though alpha blockers are firstline treatment for symptomatic BPH, they are not used exclusively for this indication and we may therefore have included men without BPH but with other indications for alpha blockers. However, although we may have

Table 3 Association between metformin and sulfonylurea initiation and occurrence of benign prostatic hyperplasia stratified by haemoglobin A1c level

\begin{tabular}{|c|c|c|c|c|c|c|}
\hline & \multicolumn{6}{|l|}{ HbA1c } \\
\hline & \multicolumn{2}{|l|}{$<7 \%$ (53 mmol $/ \mathrm{mol})$} & \multicolumn{2}{|c|}{$7 \%-<8 \%(53-<64 \mathrm{mmol} / \mathrm{mol})$} & \multicolumn{2}{|c|}{$\geq 8 \%$ (64 $\mathrm{mmol} / \mathrm{mol})$} \\
\hline & Crude HR $(95 \% \mathrm{Cl})$ & $\begin{array}{l}\text { Adj HR } \\
(95 \% \mathrm{Cl})\end{array}$ & $\begin{array}{l}\text { Crude HR } \\
\text { (95\% Cl) }\end{array}$ & $\begin{array}{l}\text { Adj HR } \\
(95 \% \mathrm{Cl})\end{array}$ & $\begin{array}{l}\text { Crude HR } \\
\text { (95\% Cl) }\end{array}$ & $\begin{array}{l}\text { Adj HR } \\
(95 \% \mathrm{Cl})\end{array}$ \\
\hline \multicolumn{7}{|l|}{ Intention to treat } \\
\hline Metformin & $\begin{array}{l}0.78 \\
(0.69 \text { to } 0.88)\end{array}$ & $\begin{array}{l}0.91 \\
(0.80 \text { to } 1.03)\end{array}$ & $\begin{array}{l}0.86 \\
(0.72 \text { to } 1.02)\end{array}$ & $\begin{array}{l}1.03 \\
(0.85 \text { to } 1.25)\end{array}$ & $\begin{array}{l}0.92 \\
(0.74 \text { to } 1.15)\end{array}$ & $\begin{array}{l}1.07 \\
(0.71 \text { to } 1.63)\end{array}$ \\
\hline \multicolumn{7}{|l|}{ As treated } \\
\hline Metformin & $\begin{array}{l}0.75 \\
(0.66 \text { to } 0.86)\end{array}$ & $\begin{array}{l}0.87 \\
(0.76 \text { to } 1.00)\end{array}$ & $\begin{array}{l}0.78 \\
(0.63 \text { to } 0.96)\end{array}$ & $\begin{array}{l}0.95 \\
(0.75 \text { to } 1.20)\end{array}$ & $\begin{array}{l}0.90 \\
(0.68 \text { to } 1.20)\end{array}$ & $\begin{array}{l}0.99 \\
(0.72 \text { to } 1.34)\end{array}$ \\
\hline Sulfonylurea & (Ref) & (Ref) & (Ref) & (Ref) & (Ref) & (Ref) \\
\hline
\end{tabular}

Crude and adjusted (adj) HRs of benign prostatic hyperplasia (BPH) defined as either a hospital-related BPH diagnosis or a first BHP-related prescription in men with diabetes according to initial treatment (intention to treat) and an as treated approach (including a 30-day washout period) stratified by haemoglobin A1c level (HbA1c).

HRs were adjusted for age, Charlson Comorbidity Index Score, calendar period of diagnosis, marital status, microvascular complications, macrovascular complications, obesity and alcohol-related disease, use of corticosteroids, use of statins and diabetes duration. 
overestimated the rate of $\mathrm{BPH}$, we found similar relative estimates when excluding alpha blockers from our BPHdefinition and our conclusion was not altered.

\section{Methodological challenges}

Also, several methodological challenges exist when comparing the effect of different GLDs and these may affect our study. We categorised GLD treatment based on the choice of treatment during the first 6 months after treatment start applying an ITT principle. Since patients may switch between different GLDs, this approach likely leads to misclassification of treatment status witch may bias the results towards the null. We did, however, find similar tendency in our results when using an as-treated approach. Although metformin and sulfonylurea both were recommended as first-line drugs in our study period and have similar expected A1c-reducing efficiency, physicians may have been more likely to prescribe sulfonylurea in patients with more severe type 2 diabetes (including complications such as early signs of renal disease or indicators of less insulin production) and metformin in obese patients where weight gain or hypoglycaemia was to be avoided. Metformin is in more recent year even used offlabel for weight reduction. ${ }^{33}$ Consistent with these expectations, we did observe different patient characteristics with metformin users being younger, more obese and fewer having microvascular or macrovascular complications. We based our information on obesity on registered ICD codes and we know these are likely substantially underreported. ${ }^{34}{ }^{35}$ Accordingly, even though we adjusted for these differences, residual confounding could still be present and could potentially mask a beneficial effect of metformin. Still, registered obesity was only weakly associated with BPH in our study.

Unfortunately, measures of $\mathrm{C}$ peptide were not available for this study period and we could not take endogenous insulin secretion into account. We also lacked information about lifestyle factors and in a previous Danish study smoking was more prevalent in users of sulfonylurea compared with users of metformin. ${ }^{17}$ Yet, an association between smoking and BPH is not clearly established. ${ }^{36}$ Furthermore, unmeasured confounding due to differences in factors related to unhealthy lifestyle and less social support between users of metformin and sulfonylurea might have influenced our findings as well.

In conclusion, metformin did not seem to substantially reduce the risk of $\mathrm{BPH}$ in men with diabetes compared with sulfonylurea.

Correction notice This article has been corrected since it first published. The provenance and peer review statement has been included.

\section{Twitter Reimar Wernich Thomsen @dr_rwt}

Contributors MN designed the study, supervised the analyses, interpreted the data and wrote the manuscript. BD contributed to the design of the study, cleaned the data, conducted the statistical analyses, interpreted the data and revised the manuscript critically. RWT contributed to the planning and design of the study, acquired the data, supervised the analyses, interpreted the data and revised the manuscript critically. All authors read and approved the final manuscript.
Funding The authors have not declared a specific grant for this research from any funding agency in the public, commercial or not-for-profit sectors.

Competing interests None declared.

Patient consent for publication Not required.

Ethics approval The study was approved by the Danish Data Protection Agency (record number 2014-54-0922 KEA-2015-4). Since no patient contact was involved, no separate permission from the Danish Scientific Ethical Committee was required according to Danish Legislation.

Provenance and peer review Not commissioned; externally peer reviewed.

Data availability statement Data may be obtained from a third party and are not publicly available. The Danish nationwide registries used for this study are kept at and data were analysed at a secured server at the Danish Health Data Authority. Data are available upon reasonable request.

Supplemental material This content has been supplied by the author(s). It has not been vetted by BMJ Publishing Group Limited (BMJ) and may not have been peer-reviewed. Any opinions or recommendations discussed are solely those of the author(s) and are not endorsed by BMJ. BMJ disclaims all liability and responsibility arising from any reliance placed on the content. Where the content includes any translated material, BMJ does not warrant the accuracy and reliability of the translations (including but not limited to local regulations, clinical guidelines, terminology, drug names and drug dosages), and is not responsible for any error and/or omissions arising from translation and adaptation or otherwise.

Open access This is an open access article distributed in accordance with the Creative Commons Attribution Non Commercial (CC BY-NC 4.0) license, which permits others to distribute, remix, adapt, build upon this work non-commercially, and license their derivative works on different terms, provided the original work is properly cited, appropriate credit is given, any changes made indicated, and the use is non-commercial. See: http://creativecommons.org/licenses/by-nc/4.0/.

\section{ORCID iDs}

Mette Nørgaard http://orcid.org/0000-0001-6110-5891

Reimar Wernich Thomsen http://orcid.org/0000-0001-9135-3474

\section{REFERENCES}

1 Maserejian NN, Chen S, Chiu GR, et al. Incidence of lower urinary tract symptoms in a population-based study of men and women. Urology 2013;82:560-4.

2 Marshall LM, Holton KF, Parsons JK, et al. Lifestyle and health factors associated with progressing and remitting trajectories of untreated lower urinary tract symptoms among elderly men. Prostate Cancer Prostatic Dis 2014;17:265-72.

3 Parsons JK, factors L. Lifestyle factors, benign prostatic hyperplasia, and lower urinary tract symptoms. Curr Opin Urol 2011;21:1-4.

4 Gandaglia G, Zaffuto E, Fossati N, et al. The role of prostatic inflammation in the development and progression of benign and malignant diseases. Curr Opin Urol 2017;27:99-106.

5 Hammarsten J, Peeker R. Urological aspects of the metabolic syndrome. Nat Rev Urol 2011;8:483-94.

6 El-Arabey AA, Abdalla M, Ali Eltayb W. Metformin: ongoing journey with superdrug revolution. Adv Pharm Bull 2019;9:1-4.

7 Haring A, Murtola TJ, Talala K, et al. Antidiabetic drug use and prostate cancer risk in the finnish randomized study of screening for prostate cancer. Scand J Urol 2017;51:5-12.

8 Preston MA, Riis AH, Ehrenstein V, et al. Metformin use and prostate cancer risk. Eur Urol 2014;66:1012-20.

9 Kuo Y-J, Sung F-C, Hsieh P-F, et al. Metformin reduces prostate cancer risk among men with benign prostatic hyperplasia: a nationwide population-based cohort study. Cancer Med 2019;8:2514-23.

10 Currie CJ, Poole CD, Gale EAM. The influence of glucoselowering therapies on cancer risk in type 2 diabetes. Diabetologia 2009;52:1766-77.

11 Farmer RE, Ford D, Mathur R, et al. Metformin use and risk of cancer in patients with type 2 diabetes: a cohort study of primary care records using inverse probability weighting of marginal structural models. Int J Epidemiol 2019;48:527-37.

12 Tsilidis KK, Capothanassi D, Allen NE, et al. Metformin does not affect cancer risk: a cohort study in the U.K. clinical practice research Datalink analyzed like an intention-to-treat trial. Diabetes Care 2014;37:2522-32.

13 Wang Z, Xiao X, Ge R, et al. Metformin inhibits the proliferation of benign prostatic epithelial cells. PLoS One 2017;12:e0173335. 
14 Murff HJ, Roumie CL, Greevy RA, et al. Thiazolidinedione and metformin use and the risk of benign prostate hyperplasia in veterans with diabetes mellitus. J Mens Health 2014;11:157-62.

15 Hong Y, Lee S, Won S. The preventive effect of metformin on progression of benign prostate hyperplasia: a nationwide populationbased cohort study in Korea. PLoS One 2019;14:e0219394.

16 Davies MJ, D'Alessio DA, Fradkin J, et al. Management of hyperglycaemia in type 2 diabetes, 2018. A consensus report by the American diabetes association (ADA) and the European association for the study of diabetes (EASD). Diabetologia 2018;61:2461-98.

17 Ulrichsen SP, Mor A, Svensson E, et al. Lifestyle factors associated with type 2 diabetes and use of different glucose-lowering drugs: cross-sectional study. PLoS One 2014;9:e111849.

18 Effect of intensive blood-glucose control with metformin on complications in overweight patients with type 2 diabetes (UKPDS 34). UK Prospective Diabetes Study (UKPDS) group. Lancet 1998;352:854-65.

19 Holman RR, Paul SK, Bethel MA, et al. 10-year follow-up of intensive glucose control in type 2 diabetes. N Engl J Med 2008;359:1577-89.

20 IDF Clinical Guidelines Task Force. Global guideline for type 2 diabetes: recommendations for standard, comprehensive, and minimal care. Diabet Med 2006;23:579-93.

21 Nathan DM, Buse JB, Davidson MB, et al. Management of hyperglycemia in type 2 diabetes: a consensus algorithm for the initiation and adjustment of therapy: a consensus statement from the American Diabetes Association and the European Association for the Study of Diabetes. Diabetes Care 2006;29:1963-72.

22 Andersen HL. Medicinsk kompendium. 16 ed. Copenhagen, Denmark: Nyt Nordisk Forlag Arnold Busck, 2004.

23 Schmidt M, Pedersen L, Sørensen HT. The Danish Civil Registration System as a tool in epidemiology. Eur J Epidemiol 2014;29:541-9.

24 Schmidt M, Schmidt SAJ, Sandegaard JL, et al. The Danish National Patient Registry: a review of content, data quality, and research potential. Clin Epidemiol 2015;7:449-90.
25 Ehrenstein V, Antonsen S, Pedersen L. Existing data sources for clinical epidemiology: Aarhus University Prescription Database. Clin Epidemiol 2010;2:273-9.

26 Selius BA, Subedi R. Urinary retention in adults: diagnosis and initial management. Am Fam Physician 2008;77:643-50.

27 Grann AF, Erichsen R, Nielsen AG, et al. Existing data sources for clinical epidemiology: the clinical laboratory information system (LABKA) research database at Aarhus University, Denmark. Clin Epidemiol 2011;3:133-8.

28 American Diabetes Association. 6. Glycemic targets: standards of medical care in diabetes-2020. Diabetes Care 2020;43:S66-76.

29 Feng Z, Zhou X, Liu N, et al. Metformin use and prostate cancer risk: a meta-analysis of cohort studies. Medicine 2019;98:e149 55-e55.

30 Farmer RE, Ford D, Forbes HJ, et al. Metformin and cancer in type 2 diabetes: a systematic review and comprehensive bias evaluation. Int $J$ Epidemiol 2017;46:745-44.

31 Carstensen B, Kristensen JK, Marcussen MM, et al. The National Diabetes Register. Scand J Public Health 2011;39:58-61.

32 Schmidt M, Schmidt SAJ, Sandegaard JL, et al. The Danish National Patient Registry: a review of content, data quality, and research potential. Clin Epidemiol 2015;7:449-90.

33 El-Arabey AA. Update on off label use of metformin for obesity. Prim Care Diabetes 2018;12:284-5.

34 Søgaard M, Heide-Jørgensen U, Nørgaard M, et al. Evidence for the low recording of weight status and lifestyle risk factors in the Danish National Registry of Patients, 1999-2012. BMC Public Health 2015;15:1320.

35 Gribsholt SB, Pedersen L, Richelsen B, et al. Validity of ICD-10 diagnoses of overweight and obesity in Danish hospitals. Clin Epidemiol 2019;11:845-54.

$36 \mathrm{Xu} \mathrm{H}, \mathrm{Fu} \mathrm{S}$, Chen Y, et al. Smoking habits and benign prostatic hyperplasia: a systematic review and meta-analysis of observational studies. Medicine 2016;95:e4565. 